\title{
Sensory conflict as a possible reason for disturbed postural stability in the children treated for cancer
}

\author{
Serafima M. Chechelnitskaia, Vladimir N. Kasatkin, Marina A. Shurupova, Irina D. Borodina, Yurij V. Sarajkin, \\ Aleksandr F. Karelin, Dmitrij V. Skvorcov, Aleksandra V. Baerbakh, Daria V. Zhuk, Vladislav A. Nikulin \\ Medical Rehabilitation Research Center "Russkoe Pole", Dmitry Rogachev National Medical Research Center for Pediatric \\ Hematology, Oncology and Immunology, Moscow, Russia
}

Prof. Serafima M. Chechelnitskaia, Medical Rehabilitation Research Center "Russkoe Pole", Dmitry Rogachev Research Medical Center for Pediatric Hematology, Oncology, and Immunology; Stremilovskoye, 142321, Chekhov District, Moscow Region, Russia
Phone: +7 (916) 8128163

E-mail: dar-2006@bk.ru

Citation: Chechelnitskaia SM, Kasatkin VN, Shurupova MA et al. Sensory conflict as a possible reason for disturbed postural stability in the children treated for cancer. Cell Ther Transplant 2019; 8(4): 68-76.

\section{Summary}

Disorders of postural resistance are widespread among the patients treated for cancer. The question of the mechanism of this phenomenon is under the study. The aim of our retrospective study was to clarify the relationship of postural instability in cancer patients with oculomotor muscle dysfunction.

\section{Patients and methods}

The study involved 291 children 5-18 years old who had cancer and were in remission state or stable clinical condition. The control group included 182 healthy children. The quality of postural balance was evaluated by stabilometric method using a computer-assisted stabilizer (Stabilan 01-2 model). The eye movements were recorded by videoculography using the Arrington eye-tracker. Regression analysis was used to assess relationships of the analyzed parameters. For explicit asymmetric distributions, we used conversion of initial values to logarithmic form and the Box-Cox transformation.

\section{Results}

The main stabilometric indicators in the position with open eyes confirmed impaired postural balance in the children who survived cancer. We have substantiated a high probability of correlation between the postural imbalance and disease factor. Improvement in stabilometric indexes with eyes closed was detected for both groups. However, this phenomenon proved to be significant and was more common among the children who survived cancer.

\section{Conclusion}

A stable relationship was found between the postural instability and altered functioning of oculomotor muscles.

\section{Keywords}

Childhood cancer, postural control, anticancer therapy, toxic effects, oculomotor muscles.

\section{Introduction}

Disturbed postural resistance is a common finding among the patients treated for cancer doseases, regardless of their exact nosological forms. Researchers describe imbalances in children treated for brain tumors $[1,2]$ and leukemia
[3], in adult people treated for lung cancer [4], breast cancer [5], leukemia, lymphomas and other solid tumors [6], etc. According to evidence-based studies meta-analyses, the percentage of leukemia survivors with disturbed postural equilibrium ranged from $27 \%$ to $69 \%$ during the treatment, being $7 \%$ to $65 \%$ at later observation terms (over 5 years) 
following the cytostatic therapy [6]. For children treated for medulloblastoma, the development of posterior cranial fossa syndrome is characteristic which may manifest with acute postural imbalance.

Damage of brain by the growing malignancy and surgical intervention are considered to be a cause of this phenomenon in the patients with tumors located at the posterior cranial fossa. However, imbalance signs in pediatric cancer patients without evident brain lesions suggest some other possible causes of postural instability. A number of researchers attribute postural imbalance to the late toxic effects of radiation therapy [6], or consequences of chemotherapy [7]. In the literature, we have encountered only a few studies on the mechanisms of impaired postural stability in the cancer patients. In particular, Gilchrist L.S. and Tanner L.R. (2018) examined the relationships of imbalance with manifestations of peripheral neuropathy [3].

In another study of adult cancer survivors treated in their childhood, it was shown that both the disease and treatment cause long-term disturbances of postural resistance in the position with open eyes. At the same time, the authors found a similar reaction of cancer survivors and healthy subjects to closing their eyes, which allowed them to confirm a preserved role of vision for postural resistance [8]. R. Leight and D. Zee (2015) showed that the brain tumors, including cerebellum, lead to serious oculomotor disturbances, in particular, saccadic dysmetry, occurence of disruptive micro- and macrosaccades, that may affect the body equilibrium [9]. Einarsson E.J. et al. (2016) showed sufficient oculomotor disorders in patients with oncological diseases which did not directly affect the central nervous system [10]. In their opinion, these disorders may be caused by toxic effects chemotherapeutic cytostatic drugs upon brain tissues after crossing the blood-brain barrier. In 2019, the same authors described increased visual dependence in people who survived childhood cancer under the age of 12 years, which is thought to explain the visual dizziness in adults who previously received chemotherapy.
The aim of our retrospective study was to clarify a relationship between the postural stability disorders in children treated for cancer, and oculomotor muscle dysfunction.

\section{Patients and methods}

The study was carried out during their rehabilitation course at the Medical Rehabilitation Research Center Russian Field. The study involved 291 children 5-18 years old who were previously treated for a brain tumor localized in the posterior cranial fossa: medulloblastoma $-58.11 \%$, piloid astrocytoma $-22.50 \%$, anaplastic ependymoma $-6.25 \%$, diffuse stem tumors $-4.36 \%$, anaplastic astrocytoma $-2.25 \%$ ganglioglioma $-2.25 \%$ and others with a frequency of $<1 \%$ and were in remission $(82.3 \%)$ or stabilization $(17.7 \%)$. In the vast majority of cases, the disease was diagnosed at an early age: up to 6 years, in $63.9 \%$ of girls and $53.7 \%$ of boys, from 7 to 11 years - in $26.9 \%$ of girls and $34.2 \%$ of boys (Fig. 1 ).

$79 \%$ of the examined children underwent radiation therapy, 75\% chemotherapy, 64\% received complex therapy, including surgical treatment, chemotherapy and radiation therapy.

According to the duration of remission at the time of examination, the patients were distributed as follows: up to 1 year $15.6 \%$, from 1 year to 3 years $-37.8 \%$, from 4 to 7 years $31.1 \%$, over 8 years $-15.6 \%$.

The control group included 182 children 6-18 years old, who were in the medical rehabilitation scientific center "Russian Field" with their siblings, and healthy children who were engaged in the group of general physical training for the first year.

The quality of the postural balance was evaluated by a stabilometric method using the computer-assisted Stabilan 01-2 device (manufacturing firm OKB RITM Russia). A stabilometric study is based on recording the parameters of the oscillations of the projection of the conditional center of mass of the person being examined on the plane of the stable platform.

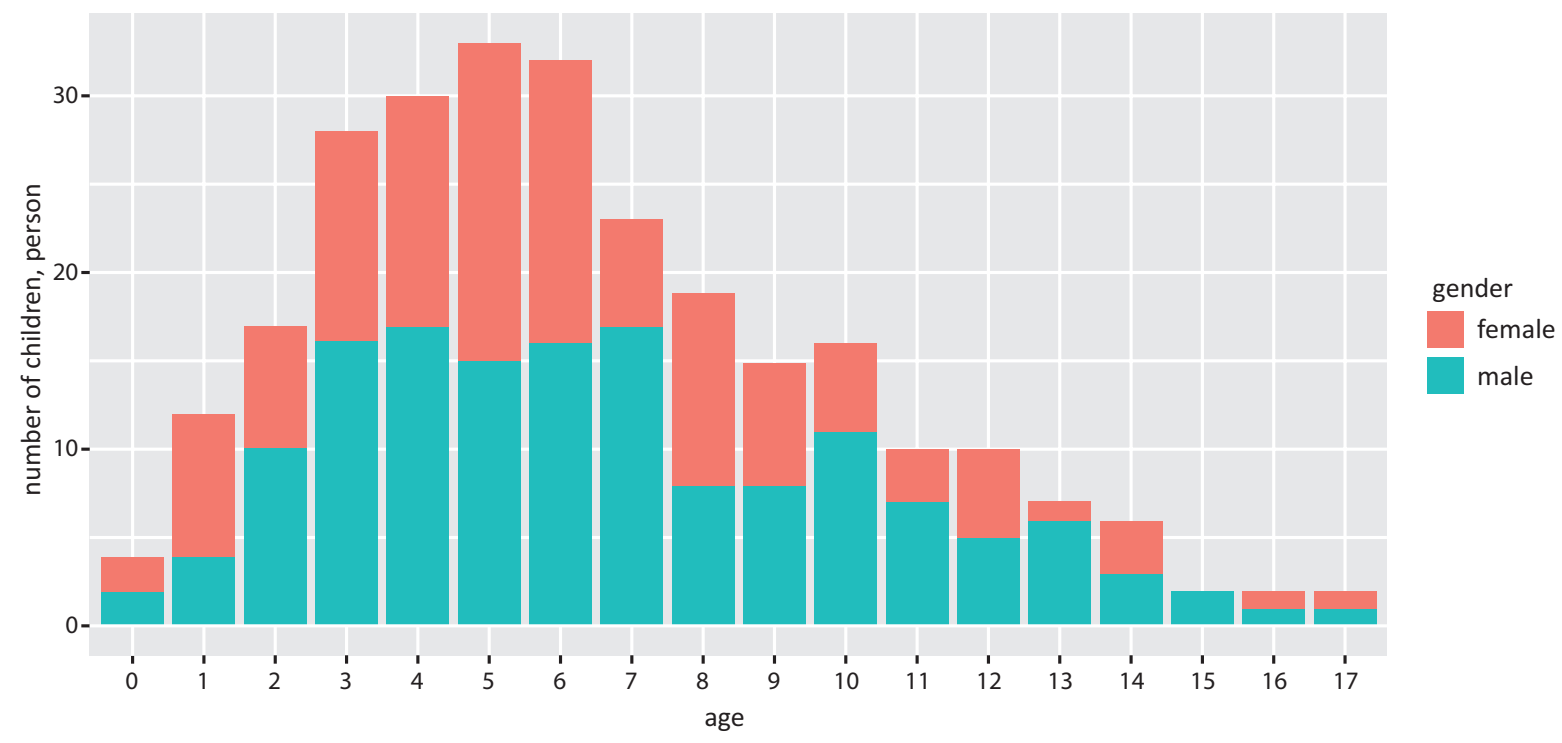

Figure 1. Distribution of the children with malignancies by their gender and age of onset. Abscissa, age of the disease onset, years; ordinate, number of cases 
Each individual test consisted of sequential trials with open and closed eyes (Romberg test) in a European installation (in heel position together, socks divorced at an angle of 30 degrees), the duration of each trial was 30 seconds [11]. The mark was stuck on the wall in front of the child. The subject should fix his eyes on it throughout the testing. We analyzed the stabilometric indicators of the displacement and dispersion of the center of human pressure in the area of support (on the reference plane, the lengths of the trajectories of the pressure center in the frontal and sagittal planes, the linear velocities of the movement of the pressure center on the reference plane, and the size of the area of the confidence ellipse of the statokinesiogram).

The center of a person's pressure on the area of support is the projection of the general center of pressure of a person's body on a horizontal plane. Displacements from the center of pressure are recorded as a statokinesiogram. The area of statokinesiogram forms an ellipse, which includes 95 percent of the fixed points, is called the area of the confidence ellipse. Figure 2 shows an example of a statokinesiogram with a confidence ellipse.

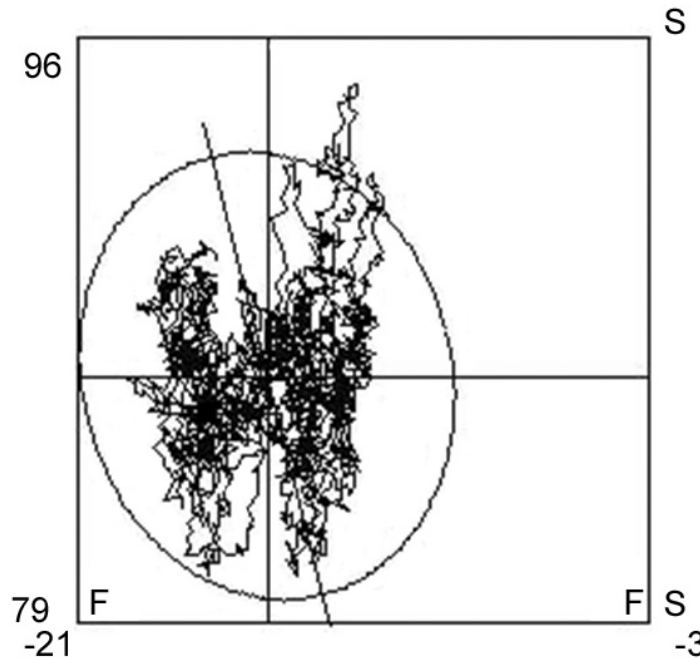

Figure 2. An example of a graphic image of a statokinesiogram. Actually, the statokinesiogram is the trajectory of pressure center oscillations during the study. The circle (a special case of an ellipse) represents a $95 \%$ confidence interval for the position of the pressure center

The patient's data were compared with gender- and agematched children from the control group. Postural balance indexes were registered in the Romberg test with open eyes. A test for fixing the gaze on a stimulus was used to evaluate the work of the saccadic system of eye movements [12], which allows one to characterize the degree of work of the oculomotor muscles, since the physiological fixation process requires establishing and maintaining fovea in one position. The required duration of fixation in the test ( 20 seconds) on each stimulus was selected, to prevent a sufficient loading of the oculomotor muscles. The test evaluates the spread and density of the gaze when fixing the patient on the stimulus.

The patient was sitting comfortably on the chair in front the monitor in the calm room for neurophysiological investi- gations. Eye movements were recorded by videoculography using an Arrington $60 \mathrm{~Hz}$ eye-tracker glasses. Patient's head was fixed by a frontal chin support to minimize head movements. Functioning of the oculomotor muscles was evaluated by the gaze fixation test on the stimulus (Danilov et al., 2015) [12]. The stimulus were presented on a Samsung 23 -inch screen (with a resolution of $1920 \times 1080$ pixels) at a distance of $60 \mathrm{~cm}$ from the subjects' eyes, while occupied about $45^{\circ}$ horizontally and $26^{\circ}$ vertically of their visual field. The stimulating object (a green dot on the screen) had a size of $\sim 1^{\circ}$, having been sequentially moved in the left/right positions by $15^{\circ}$, and at the top/bottom direction, by $8^{\circ}$ for $20 \mathrm{~s}$ for each position. Dispersion and density of the gaze fixation points on the every stimulus were evaluated. Raw dispersions of gaze fixation points were filtered in $\pm 2 \sigma$ of coordinates' distribution and fitted by ellipse Matlab function "fit_ellipse". Then the squares of the obtained ellipses were counted in $\mathrm{deg}^{2}$. Densities of the gaze fixation points were counted as a ratio of the number of fixation points to the ellipse square. The larger squares of the ellipses and the lower densities of the points reveal the more unstable gaze fixation.

Statistical evaluation of the results was performed with a modification of the Student t-test (Welch test), which suggests that the variances of the compared populations are not equal. To model relationships between of the analyzed indexes, regression analysis was used, which allowed us to analytically present the relationship models between appropriate indexes, and to quantify relative influence for distinct factors. In the course of statistical modeling of explicit asymmetric distributions, we used conversion of initial values to logarithmic form and the Box-Cox transformation.

\section{Results}

To assess the postural balance in patients treated for tumors of the posterior cranial fossa, we analyzed the stabilometric indicators of the displacement and dispersion of the fixation points of the pressure center on the reference plane, the length of the trajectories of the pressure center in the frontal and sagittal planes, the linear velocities of the pressure center on the reference plane and the magnitude areas of the confiding ellipse of the statokinesiogram. The results were compared with homologous children from the control group. Indicators of postural balance were recorded in the Romberg test with open eyes. The results are presented in Table 1.

In our study, the average size of the estimated ellipse area in children of the main group in the position with open eyes was $673 \pm 1201.1 \mathrm{~mm}^{2}$, thus being significantly differed from the average values in the control group $\left(258.9 \pm 162.5 \mathrm{~mm}^{2}\right)$. To confirm the hypothesis about the relationship between the postural balance and the disease, a nonlinear (exponential) regression model was constructed for the Ellipse Area indicator:

$$
\log (\text { Ells })=6.7-0.059 \text { full.year }+0.104 \text { gender }-0.57 \mathrm{grp},
$$$$
R^{2}=0.103, p<0,05 \text {. }
$$

where $\log ($ Ells) is the logarithm (natural) of the area of the ellipse.

gender $=1$ - boys, 0 - girls

grp $=1$ - healthy controls; 0 , treated patients. 
Table 1. Indexes of postural balance in children treated for brain tumor, and in healthy children using Romberg test with open eyes

\begin{tabular}{|c|c|c|c|c|c|}
\hline \multirow{2}{*}{ Parameters } & \multicolumn{2}{|c|}{ Main group ( $n=283$ ) } & \multicolumn{2}{|c|}{ Control group ( $n=39$ ) } & \multirow{2}{*}{$\begin{array}{l}\text { Significance levels, } \\
\text { p values }\end{array}$} \\
\hline & Mean & Std. dev. & Mean & Std. dev. & \\
\hline Center of pressure frontal displacement, mm & -0.1 & 13.4 & -0.2 & 7.6 & 0.9027 \\
\hline Center of pressure sagittal displacement, mm & -55.8 & 22.7 & -64.2 & 18.4 & 0.01223 \\
\hline Center of pressure frontal dispersion, $\mathrm{mm}$ & 5.7 & 3.8 & 3.6 & 1.3 & $<0.0000$ \\
\hline Center of pressure saggittal dispersion, $\mathrm{mm}$ & 6.5 & 3.7 & 4.7 & 1.6 & $<0.0000$ \\
\hline $\begin{array}{l}\text { The average speed of center of pressure } \\
\text { movement, } \mathrm{mm} / \mathrm{sec} \text {. }\end{array}$ & 20.1 & 15.2 & 14.5 & 4.4 & $<0.0000$ \\
\hline Confidence ellipse area, mm² & 673.1 & 1201.1 & 258.9 & 162.5 & $<0.0000$ \\
\hline Movement Estimation, conditional unit & 51.5 & 15.7 & 56.8 & 13.2 & 0.02696 \\
\hline The quality of the equilibrium function, $\%$ & 53.6 & 22.1 & 63.8 & 14.1 & 0.0003 \\
\hline Linear average speed, mm/sec. & 20.4 & 15.4 & 14.5 & 4.4 & $<0.0000$ \\
\hline
\end{tabular}

Age of children (full_years), and disease state (grp) proved to be the statistically significant factors in this model. According to the model, the logarithm of ellipse area in healthy children was lower by $0.57(\mathrm{p}<0.000)$.

In order to study potential contribution of altered vision in the postural control, we analyzed the change in the Romberg test parameters when the patient changes the position with open eyes (EO) to the pose with closed eyes (EC). For analysis, the relative dynamics of indexes were calculated by the formula:

$\Delta_{\text {percent }}=\frac{X_{I O}-X_{I 3}}{X_{\Gamma O}} * 100 \% \Delta_{\text {percent }}=\frac{X_{X E O}-X_{X E C C}}{X_{X E O}} * 100 \%$

where

$\Delta_{\text {percent }}$ - the percentage changes of stabilometric indexes when closing the eyes;

$X_{T O}$ - the value of the index in EO position;

$X_{\Gamma 3}$ - the value of the index in EC position.
When evaluating the following indices: Assessment of movement and Quality of the equilibrium function, a minus sign was introduced before the formula, due to their special calculation modes:

$\Delta_{\text {percent }}=-\frac{X_{\Gamma O}-X_{\Gamma 3}}{X_{\Gamma O}} * 100 \%$

As a result, we have calculated the factors characterizing changes of stabilometric indexes when turning off the vision. The values of the coefficient equal to "0" and higher denoted the improvement of stabilometric values when closing the eyes, whereas a negative value meant their impairment (Table 2).

More often, the shutdown of vision led to a positive change in the mentioned indexes. Assessment of movement and Displacement of the center of pressure along the sagittal axis $(68.5 \% / 61.1 \%$ of pediatric patients, and $30.8 \% / 33.3 \%$ in the control group, respectively), as seen from Table 3.

Table 2. Increases in the indicators of the postural balance of children treated for cancer and their healthy peers in the Romberg test when moving from the 0pen eyes to the Closed eyes position

\begin{tabular}{|l|l|l|l|}
\hline \multirow{2}{*}{ Parameters } & \multicolumn{2}{l|}{ Average growth of indexes } & \multirow{2}{*}{$\begin{array}{l}\text { Significance levels, } \\
\text { p values }\end{array}$} \\
\cline { 2 - 3 } & Main group & Control group & \\
\hline Center of pressure frontal displacement, $\mathrm{mm}$ & -0.336 & -1.125 & 0.4987 \\
\hline Center of pressure sagittal displacement, $\mathrm{mm}$ & -0.007 & 0.021 & 0.3857 \\
\hline Center of pressure frontal dispersion, $\mathrm{mm}$ & -0.084 & -0.045 & 0.5629 \\
\hline Center of pressure sagittal dispersion, $\mathrm{mm}$ & -0.043 & -0.043 & 0.9904 \\
\hline The average speed of center of pressure movement, $\mathrm{mm} / \mathrm{sec}$. & -0.173 & -0.115 & 0.1970 \\
\hline Confidence ellipse area, mm ${ }^{2}$ & -0.132 & -0.130 & 0.9825 \\
\hline Movement Estimation, conditional unit & 0.170 & 0.100 & 0.0652 \\
\hline The quality of the equilibrium function, \% & -0.067 & -0.050 & 0.6204 \\
\hline Linear average speed, $\mathrm{mm} / \mathrm{sec}$. & -0.182 & -0.114 & 0.1469 \\
\hline
\end{tabular}


Table 3. Frequencies of "atypical" reactions in the Romberg position with closed eyes, \%

\begin{tabular}{|l|l|l|l|}
\hline \multirow{2}{*}{ Parameters } & \multicolumn{2}{|l|}{$\begin{array}{l}\text { Percentage of children with } \\
\text { improvement }\end{array}$} & \multirow{2}{*}{$\begin{array}{l}\text { Significance levels, } \\
\text { p values }\end{array}$} \\
\cline { 2 - 3 } & Main group & Control group & \\
\hline Center of pressure frontal displacement, $\mathrm{mm}$ & $55.0 \%$ & $17.9 \%$ & $<0.0000$ \\
\hline Center of pressure sagittal displacement, $\mathrm{mm}$ & $61.1 \%$ & $33.3 \%$ & 0.0014 \\
\hline Center of pressure frontal dispersion, $\mathrm{mm}$ & $47.9 \%$ & $23.1 \%$ & 0.0016 \\
\hline Center of pressure saggittal dispersion, $\mathrm{mm}$ & $45.7 \%$ & $15.4 \%$ & $<0.0000$ \\
\hline The average speed of center of pressure movement, $\mathrm{mm} / \mathrm{sec}$. & $27.9 \%$ & $7.7 \%$ & 0.0002 \\
\hline Confidence ellipse area, $\mathrm{mm}^{2}$ & $43.2 \%$ & $20.5 \%$ & 0.0026 \\
\hline Movement Estimation, conditional unit & $68.5 \%$ & $30.8 \%$ & $<0.0000$ \\
\hline The quality of the equilibrium function, $\%$ & $27.3 \%$ & $7.7 \%$ & 0.0003 \\
\hline Linear average speed, $\mathrm{mm} / \mathrm{sec}$. & $27.0 \%$ & $7.7 \%$ & 0.0003 \\
\hline
\end{tabular}

In the main group, the area of the confidence ellipse decreased in $43.2 \%$ of children by an average of $33.4 \%$. Similar dynamics was noted in $20.5 \%$ of the examined children, the average decrease in area was $29.6 \%$ (Fig. 3). Moreover, the Romberg coefficient averaged $113 \%$ both in the main group and in the control group.

To test the hypothesis about the relationship between postural control and oculomotor activity, we analyzed the results of examination of children treated for tumors of the posterior cranial fossa, on an i-tracking. The oculomotor muscles perform fast saccadic eye movements necessary for fixing the gaze on the object, a point in space, etc., due to which the brain receives visual information. The saccadic system is a complex hierarchical system in which many brain structures are involved [19]. The variable measured in the i-tracking is the area of ellipses $\left(\mathrm{deg}^{2}\right)$, in terms of the content and type of the calculation, it is related to the stabilometric parameter the ellipse of the statokinesiogram. The larger is the area of the ellipse, the less stable the gaze is kept. Vice versa, the gaze fixation of the gaze is impaired due to various involuntary saccadic movements (disruptive, intrusive macro- and micro-amplitude involuntary saccades) and nystagmus. The second variable density of gaze fixation, with $95 \%$ of points fitting the ellipse area within a definite time period. It characterizes the presence or absence of large-amplitude movements, since with large-amplitude movements, the area of the ellipse increases when the gaze is fixed, and the density of the gaze positions, on the contrary, decreases.

We did not find any correlations between the absolute stabilometric indexes and saccadic activity. At the same time, we found a connection between saccadic activity indexes and increased stabilometry indexes in the Romberg test upon transition from open to closed eyes. Indicators of saccadic activity showed asymmetric distribution. Therefore, a power-law transformation of initial data by the Box-Cox method was performed, in order to identify their relationships with stabilometry indexes.

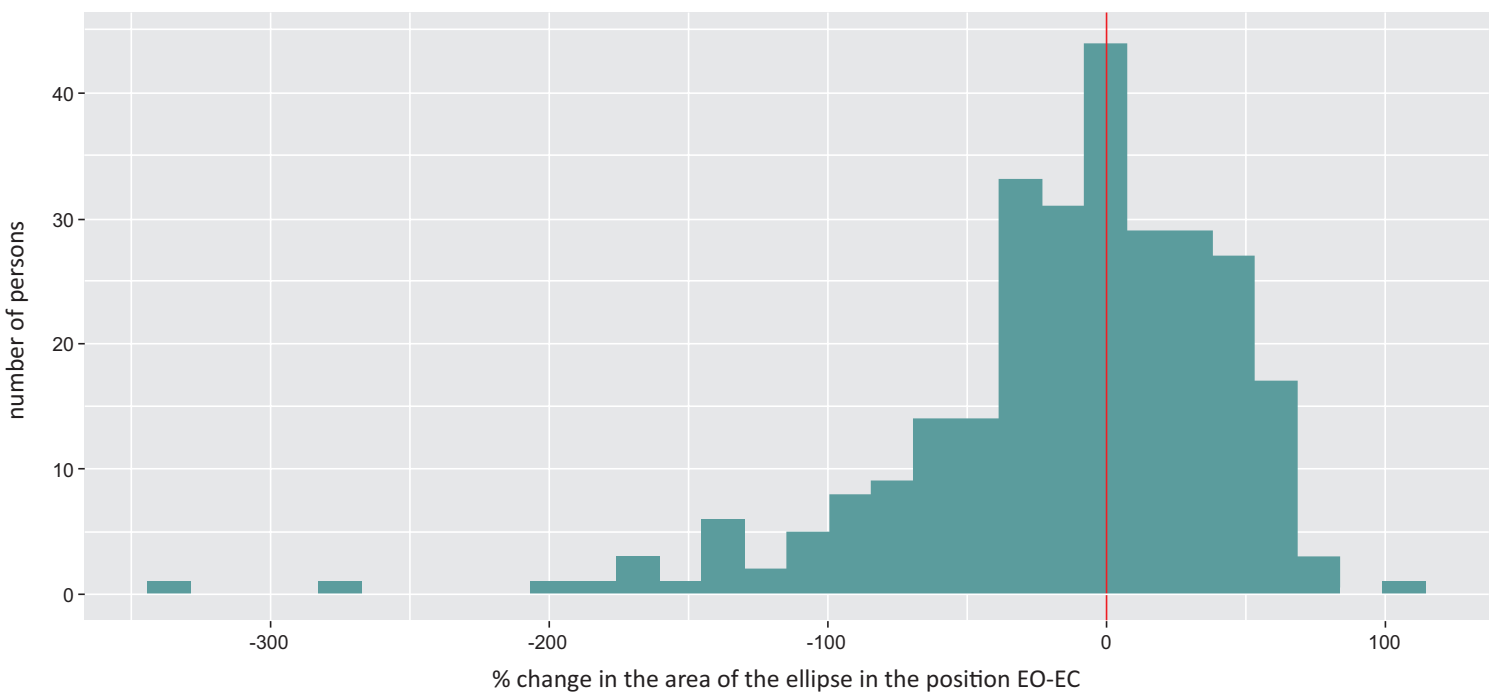

Figure 3. The allocation of growth rates of the indicator Ellipse area increments in the Romberg test during the transition from open to closed eyes in children of the main group 
The simulation results showed that the mode of relationships between the saccadic activity indicators and incrementing stabilometric indices corresponded to linear regression. A moderate correlation between the conventional elliptic area during gaze fixation and increased stabilometry indices was shown by means of this model; the multiple correlation coefficient is in the range between 0.35 and 0.62 . The contribution of explained variance $\left(\mathrm{R}^{2}\right)$ was in the range of $13.2 \%$ to $38.0 \%$.

The moderate correlation between the density of points in the ellipse during gaze fixation and the growth of stabilometry indicators was also demonstrable, with multiple correlation coefficients of 0.38 to 0.59 . The impact of explained variance $\left(\mathrm{R}^{2}\right)$ is in the range of $14.4-34.5 \%$. The correlation coefficients of individual indicators are shown in Table 4.

\section{Discussion}

The physical status of children who survived cancer, has become the subject of an active study in connection with the successes of modern medicine. The end of anti-cancer treatment does not mean complete recovery of the patient. Moreover, aggressive anti-cancer treatment leads to the development of multiple complications that worsen the quality of life and reduce the predicted life expectancy $[13,14,7]$. The data obtained by researchers indicate the need for physical activity programs aimed specifically at approaches to minimizing physical limitations. One of these limitations is a violation of the postural balance.

Imbalances in the body in works on children who have survived cancer, are usually detected by the Bruninks-Ozeretsky test, which allows you to study the whole range of motor qualities $[8,5,1]$. According to Gilchrist LS, Tanner LR (2018), 78\% of children receiving chemotherapy courses for cancer showed reduced balance on treatment, 6 months after the end of treatment, the percentage of children with reduced rates decreased to 53\% [3]. This means that more than half of the children still had difficulty holding their posture. In studies of Piscione PJ, Bouffet E et al. (2014), conducted with the participation of children with tumors of the posterior cranial fossa (cerebellar astrocytoma $43.3 \%$ and medulloblastoma 40\%), a significant decrease in balance indicators was recorded in $70 \%$ of the examined [1].
We applied the method of stabilometry to assess the postural balance in children 5-18 years old. Differences between the indicators of children of the main and control groups reached the level of statistical significance, excluding the indicator, i.e., displacement length of the center of pressure in frontal plane. But at the same time, the difference in almost all parameters did not reach the level of physiological significance, since in both groups the spread of the numbers was very large.

Einarsson E-J, Patel M, et al. (2016) also described the absence of a significant difference between people who survived childhood cancer and healthy control in a calm stance [10]. But at the same time they found that former patients spend significantly more energy than healthy people to maintain vertical balance. In our further analysis, we plan to study the features of energy consumption for maintaining a vertical posture in children.

The area of confidence ellipse proved to be the most sensitive parameter in our study, since the average size of the area of the ellipse in children of the main group in the position with open eyes was $673 \pm 1201.1 \mathrm{~mm}^{2}$, and in the control group $258.9 \pm 162.5 \mathrm{~mm}^{2}$. The constructed model of nonlinear (exponential) regression for the Ellipse area indicator allowed us to confirm the relationship between the ellipse area and the disease. Consequently, a combination of not very physiologically significant deviations in the stabilometry indicators confirms the presence of postural disorders.

The leading role of vision in postural control in cancer survivors is confirmed by Einarsson E-J, Patel M, et al. (2016). According to them, vision significantly increased postural stability in both former patients and the control group. Both of them spent less energy on maintaining the posture in the position with open eyes. The authors found no evidence of dependence on chemotherapy [10].

The data given indicate that in the position with the eyes closed we are entitled to expect a significant deterioration in the main indicators of stabilometry. Perhaps even more significant than in healthy children. It is generally accepted that a healthy person has a normal reaction from the body balance control system to turning off the visual analyzer - an increase in the fluctuation of the center of pressure [15].

Table 4. Matrix of paired correlation coefficients between the increment of stabilometry indicators and parameters of saccadic activity after the Box-Cox transformation

\begin{tabular}{|c|c|c|c|c|c|c|c|c|}
\hline \multirow{2}{*}{ Relative changes: } & \multicolumn{4}{|c|}{$\begin{array}{l}\text { The ellipse area upon fization of gaze, } \\
\text { relative correlation quotients }\end{array}$} & \multicolumn{4}{|c|}{$\begin{array}{l}\text { Density of points of gaze positions in an } \\
\text { ellipse }\end{array}$} \\
\hline & Left & Up & Right & Down & Left & Up & Right & Down \\
\hline $\begin{array}{l}\text { frontal center of pressure } \\
\text { dispersion, mm }\end{array}$ & $0.511^{\star}$ & $0.406^{\star}$ & $0.468^{*}$ & $0.363^{*}$ & $-0.483^{\star}$ & $-0.410 *$ & $-0.476^{\star}$ & -0.380 * \\
\hline $\begin{array}{l}\text { sagittal center of pressure } \\
\text { dispersion, mm }\end{array}$ & -0.027 & 0.107 & 0.139 & 0.061 & 0.047 & -0.103 & -0.124 & -0.089 \\
\hline $\begin{array}{l}\text { the average speed of the center } \\
\text { of pressure movement } \mathrm{mm} / \mathrm{sec} \text {. }\end{array}$ & $0.444^{*}$ & $0.373^{\star}$ & $0.415^{\star}$ & 0.296 & $-0.434^{\star}$ & -0.320 & $-0.415^{\star}$ & -0.289 \\
\hline confidence ellipse area, mm² & 0.325 & $0.362^{\star}$ & $0.417^{\star}$ & 0.324 & -0.301 & $-0.353^{\star}$ & $-0.418^{\star}$ & $-0.354^{*}$ \\
\hline
\end{tabular}

Note: ${ }^{*}$, correlation quotients are statistically significant at $\mathrm{p}<0.05$ 
In our studies, we often encountered the opposite reaction the postural balance in the position with the eyes closed improved.

The analysis of the coefficients of growth indicators obtained by us when closing the eyes showed that a positive reaction of the postural balance to turning off the vision occurs both among children treated for tumors of the posterior cranial fossa and among their healthy peers. In the group of treated children, this phenomenon occurred reliably and significantly more often. But at the same time, the values of the average coefficients of the indicators were comparable, their differences did not reach the level of statistical significance.

The most sensitive to eye closure were the indicators Assessment of movement and Displacement of the center of pressure along the sagittal. These results are consistent with the data of Andrea Berensci et al. (2005) [16] that the amplitudes of postural vibrations are greater when stimuli are presented for central vision than for peripheral vision conditions. Our study did not include children with clinically expressed central vision problems, as this was an exclusion criterion. Nevertheless, it cannot be ruled out that one of the reasons for improving the postural balance is subclinical visual acuity.

The indicator Assessment of movement should not be associated with the acuity of central vision, since it is calculated as the ratio of the indicators "Curve Length" and "Average Dispersion" and reflects the spread of fluctuations (tremor).

Earlier, a number of authors showed that patho-biomechanical changes in the structures richest in proprioreceptors (neck muscles, oculomotor muscles, chewing muscles) cause a mismatch between the real and perceived CNS position of the body parts $[8,16]$. We tested the hypothesis about the role of oculomotor muscle dysfunction in disturbing postural balance in children treated for tumors of the posterior cranial fossa. Absolute indicators of stabilometry in an upright posture with open eyes were not associated with indicators of saccadic activity. At the same time, the relationship between the coefficients of change in the indicators of stabilometry when closing the eyes with the area of the ellipse of the fixation points of the gaze corresponded to linear regression and was stable in average. The share of the explained variance reached $38.0 \%$. Equally expressed and stable was the relationship between the coefficients of change in the indicators of stabilometry and the density of the points of fixation of the gaze in the ellipse.

Since when closing the eyes there is not only a shutdown of visual afferentation, but also a decrease in the activity of the oculomotor muscles, the latter may explain the improvement in postural balance when closing the eyes. The validity of this conclusion is indirectly confirmed by a number of works.

Einarsson E-J, Patel M, et al. (2016) studied oculomotor activity in adults who received chemotherapy in childhood for a solid cancerous tumor that did not affect the central nervous system. According to them, the temporal control of smooth tracking speed (speed accuracy) was noticeably worse $(\mathrm{p}<0.001)$, and saccades had a disproportionately lower amplitude in survivors of childhood cancer compared with healthy subjects [10]. Patients treated before 12 years old had a more expressed oculomotor deficiency. Patients who survived childhood cancer experienced subjective symptoms of visual impairment (70\%), sensations that things around them revolved or moved (87\%). Several subjective symptoms were largely associated with a deficiency of oculomotor characteristics.

In our study, the phenomena of saccadic dysmetry, regardless of the direction of gaze, were associated with coefficients reflecting the change in the indicators of movement of the fixation points of the center of pressure of the body on the surface in the frontal plane and their derivatives, which is consistent with the statement of Andrea Berensci et al. [17] on the role of peripheral vision in postural stability. Changes in indicators in the sagittal plane were either not connected at all, or with a small number of variables, which indicates the absence of influence of central vision.

\section{Conclusion}

We have confirmed that, already early after the end of cytostatic treatment, the children who survived cancer develop postural balance disorders associated with the disease factor. We have revealed an improvement of postural control when closing eyes and its connection with saccadic dysmetria, thus allowing to consider this phenomenon to be a result of damage to oculomotor muscles and offering new tools and methods for rehabilitation of cancer patients.

\section{Conflict of interest}

None reported.

\section{References}

1. Piscione PJ, Bouffet E, Mabbott DJ, Shams I, Kulkarni AV. Physical functioning in pediatric survivors of childhood posterior fossa brain tumors. Neuro Oncol. 2014; 16(1): 147155.

2. Toy SL, Senesac C, Trombini A. Postural control and balance training in a pediatric patient status post medulloblastoma removal. Pediat Phys Ther. 2006; 18(1):107-108.

3. Gilchrist LS, Tanner LR. Short-term recovery of balance control: association with chemotherapy-induced peripheral neuropathy in pediatric oncology. Pediat Phys Ther. 2018; 30(2): 119-124.

4. Kumar V, Vincent D, Butler JS, Xu Y. Ataxia in long-term survivors of lung cancer after whole brain radiation therapy (WBRT). J Clin Oncol. 2016; 34(Suppl.15):e20656-e20656.

5. Bahcaci U, Demirbuken I. Effects of chemotherapy process on postural balance control in patients with breast cancer. Indian J Cancer. 2019; 56(1):50-54.

6. Varedi M, McKenna R, Lamberg EM. Balance in children with acute lymphoblastic leukemia. Pediat Int. 2017; 59:293302.

7. Ness KK, Krull KR, Jones KE, Mulrooney DA, Armstrong GT, Green DM, Chemaitilly W, Smith WA, Wilson CL, Sklar CA, Shelton K, Srivastava DK, Ali S, Robison LL, 
Hudson MM. Physiologic frailty as a sign of accelerated aging among adult survivors of childhood cancer: A report from the St. Jude Lifetime Cohort study. J Clin Oncol. 2013; 31(36):4496-4503.

8. Einarsson EJ, Patel M, Petersen H, Wiebe T, Fransson PA, Magnusson $\mathrm{M}$, et al. Elevated visual dependency in young adults after chemotherapy in childhood. PLoS One. 2018; 13(2):e0173678.

9. Leigh RJ, Zee DS. The Neurology of Eye Movements. 5th edition. New York, NY: Oxford University Press: 2015, 1075 p.

10. Einarsson EJ, Patel M, Petersen $\mathrm{H}$, et al. Oculomotor deficits after chemotherapy in childhood. PLoS One. 2016; 11(1): e0147703.

11. Nigamadyanov NR. Computer-assisted stabilometry in diagnostics and correction of postural disturbances in children with spinal pathology. Ref. PhD Thesis: Moscow. 2017: 1-20 (In Russian).

12. Danilov Y, Kaczmarek K, Skinner K, Tyler M. Cranial Nerve Noninvasive Neuromodulation. In: Brain neurotrauma: molecular, neuropsychological, and rehabilitation aspects. Taylor \& Francis, Boca Raton (FL): CRC Press. 2015, Chapter 44.

13. Hudson MM, Oeffinger KC, Jones K, Brinkman TM, Krull KR, Mulrooney DA, Mertens A, Castellino SM, Casillas J, Gurney JG, Nathan PC, Leisenring W, Robison LL, Ness KK. Age-dependent changes in health status in the Childhood Cancer Survivor cohort. J. Clin. Oncol. 2015; 33(5):479-491.

14. Taylor N, Absolom K, Michel G, Urquhart T, Gerrard M, Jenkins A, Lee V, Vora A, Eiser C. Comparison of self-reported late effects with medical records among survivors of childhood cancer. Eur. J. Cancer. 2010; 46(6):1069-1078.

15. Lysenko VV, Mirzoeva EV, Ostrikov AP, Bozhkov AV. Interaction between disturbed statics and vision quality in sports. Molodoy Ucheny. 2016; 24: 565-568 (In Russian).

16. Boulanger M, Giraudet G, Faubert J. Interaction between the oculomotor and postural systems during a dual-task: Compensatory reductions in head sway following visually-induced postural perturbations promote the production of accurate double-step saccades in standing human adults. PLoS One. 2017; 12(3): e0173678.

17. Berensci A, Ishihara M, Imanaka $\mathrm{K}$. The functional role of central and peripheral vision in the control of posture. Human Movement. 2005; 24(5-6):689-709. 


\title{
«Сенсорный конфликт» как возможная причина нару- шения постуральной устойчивости детей, лечившихся от онкологических заболеваний
}

\author{
Серафима М. Чечельницкая, Владимир Н. Касаткин, Марина А. Шурупова, Ирина Д. Бородина, Юрий В. Сарайкин, \\ Александр Ф. Карелин, Дмитрий В. Скворцов, Александра В. Баербах, Дарья В. Жук, Владислав А. Никулин \\ Лечебно-реабилитационный научный центр «Русское поле», Национальный медицинский исследовательский центр \\ детской гематологии, онкологии и иммунологии им. Дмитрия Рогачева, Москва, Россия
}

\section{Резюме}

Нарушения постуральной устойчивости широко распространено среди пациентов, лечившихся от онкологических заболеваний. Вопрос о механизмах этого явления находится на стадии изучения. Целью проведенного нами ретроспективного исследования было уточнение связи постуральной нестабильности онкологических пациентов с дисфункцией глазодвигательных мышц. В исследовании приняли участие 291 ребенок 5-18 лет, перенесших онкологическое заболевание и находящихся в стадии ремиссии или стабилизации. В контрольную группу вошли 182 здоровых ребенка.

Качество постурального баланса оценивалось методом стабилометрии на компьютерном стабилоанализаторе «Стабилан 01-2». Регистрация движений глаз производилась методом видеокулографии с помощью айтрекера Arrington. Для моделирования взаимосвязи анализируемых показателей использовался регрессионный анализ, для явно выраженных асимметричных распределений применялось преобразование исходных значений в виде логарифмирования и степенного преобразование Бокса-Кокса (Box-Cox transformation).
Основные показатели стабилометрии в позе с открытыми глазами подтвердили нарушения постурального баланса у детей, переживших рак. Математически была обоснована высокая вероятность связи дисбаланса с фактором заболевания. Улучшение показателей стабилометрии при закрывании глаз выявлено в обеих группах, но среди детей, переживших рак, этот феномен выявлялся достоверно и значимо чаще. Обнаружена устойчивая связь между постуральной нестабильностью и нарушением работы глазодвигательных мышц.

\section{Ключевые слова}

Рак у детей, постуральный контроль, противоопухолевая терапия, токсические эффекты, глазодвигательные мышцы. 